\title{
PENGARUH TOTAL QUALITY MANAGEMENT (TQM) TERHADAP KINERJA MANAJERIAL DENGAN SISTEM PENGHARGAAN SEBAGAI VARIABEL PEMODERRASI (STUDI PADA SUPERMARKET DI MATARAM)
}

\author{
Oleh \\ Sri Ayu Febrianti'), I Gusti Putu Bagus Suastina' ${ }^{2)}$ \& Muhammad Bahrul Ulum ${ }^{3)}$ \& Eka \\ Putrianti $^{4}$ \\ 1,2,3,4 Dosen STIE 45 Mataram \\ Email : ${ }^{1} \underline{\text { aditzfa85@gmail.com, }}, \underline{\text { Suastina1957@ gmail.com \& }{ }^{3} \text { micu1307@gmail.com }}$
}

\begin{abstract}
The aim of this study is to analyzed the effect of Total Quality Management (TQM) on managerial performance and the reward system as the moderating variable that may affect the relationship of Total Quality Management (TQM) on managerial performance. The type of this research is associative. Respondents consisting of managers and staff with the lowest level of supervisor in the entire supermarket in Mataram, as many as 66 respondents. Sampling technique is census. Using simple regression analysis and Moderated Regression Analysis (MRA) as analysis. The results showed that TQM significantly influence the performance of managerial and the reward system doesn't influence the relationship of TQM on managerial performance.
\end{abstract}

Keywords : Total Quality Management (TQM), Reward System, Managerial Performance, \& Supermarket.

\section{PENDAHULUAN}

Persaingan yang ketat pada industri bisnis di Indonesia saat ini memberikan pengaruh baik secara langsung maupun tidak langsung terhadap setiap perusahaan yang ada. Setiap perusahaan dituntut untuk meningkatkan efektivitas dan efisiensi dalam menjalankan pekerjaannya agar dapat memperoleh pelanggan dan dapat menjadi market leader dari produk yang mereka tawarkan.

Supermarket adalah salah satu bentuk retailing semacam perusahaan atau industri dalam hal ini industri dagang dan sebagai penyedia barang serta jasa dengan mutu dan pelayanan yang baik kepada konsumen. Barang yang dijual memiliki variasi jenis yang beragam dan mempunyai kualitas yang relatif lebih terjamin karena melalui penyeleksian terlebih dahulu secara ketat sehingga barang yang tidak memenuhi persyaratan kualifikasi akan ditolak. Menghadapi persaingan antar supermarket di wilayah Kota Mataram menyebabkan para manajer perusahaan tidak dapat lagi menerapkan cara-cara tradisional dalam melakukan proses perencanaan dan pengendalian aktivitas perusahaan. Pihak manajemen dituntut untuk selalu memperhatikan kebutuhan dan keinginan konsumen serta berusaha memenuhi apa yang mereka harapkan dengan cara yang lebih memuaskan daripada yang dilakukan pesaing.

Salah satu pendekatan dalam menghadapi era globalisasi karena persaingan yang semakin ketat ini adalah dengan menerapkan konsep Total Quality Management dalam industri manufaktur dan jasa serta strategi mempersiapkan diri dengan tujuan meningkatkan kualitas proses produksi dan produktivitas secara optimal dan berkelanjutan. Total Quality Management yang disingkat dengan TQM merupakan suatu pendekatan dalam menjalankan usaha yang mencoba untuk memaksimumkan daya saing organisasi melalui perbaikan terus-menerus atas produk, jasa, manusia, proses, dan lingkungannya (Malik, 2010). TQM merupakan suatu sistem yang dirancang sebagai kesatuan yang memfokuskan pada pendekatan pelanggan dengan meningkatkan kualitas produk dan pelayanan. TQM meningkatkan produktivitas dengan mengurangi perilaku yang tidak produktif (Karahan, 2012). 
Perusahaan yang berusaha melakukan perbaikan terus-menerus biasanya menggunakan teknik TQM. Beberapa perusahaan yang telah menerapkan teknik TQM ada yang telah berhasil meningkatkan kinerjanya, tetapi ada juga yang belum mampu meningkatkan kinerja. Penerapan teknik TQM yang tinggi dengan pemberian kompensasi yang lebih baik kepada manajer juga memotivasi dalam peningkatan kinerja. Penghargaan (kompensasi) adalah apa yang diterima para karyawan sebagai ganti kontribusi karyawan kepada organisasi. Semakin besar perhatian perusahaan terhadap kebutuhan karyawannya maka perusahaan tersebut akan mendapat timbal balik yang sesuai yaitu maksimalisasi dalam produktivitas kerja (Nurfitriana et al., 2005).

Agar pembahasan dapat lebih terfokus, maka dilakukan pembatasan masalah pada pengaruh Total Quality Management (TQM) terhadap kinerja manajerial serta pengaruh Total Quality Management (TQM) terhadap kinerja manajerial dengan pemoderasi variabel sistem penghargaan. Sehubungan dengan permasalahan yang diajukan maka penelitian ini bertujuan untuk menganalisis mengenai pengaruh Total Quality Management (TQM) terhadap kinerja manajerial serta menganalisis mengenai pengaruh Total Quality Management (TQM) terhadap kinerja manajerial dengan pemoderasi variabel sistem penghargaan.

Manfaat penelitian ini adalah bahwa secara akademik sebagai syarat beban kerja Dosen pada LLDIKTI Wilayah VIII Bali NTB dan secara teoritis sebagai implementasi pengaruh Total Quality Management (TQM) terhadap kinerja manajerial yang dimoderasi oleh sistem penghargaan terhadap fenomena di supermarket serta secara praktis dapat memberi tambahan informasi bagi pihak manajemen yang bermanfaat sebagai pertimbangan dalam meningkatkan kinerja manajerial agar lebih produktif, efektif, dan efisien.

\section{LANDASAN TEORI Kinerja Manajerial}

Kinerja adalah hasil kerja yang dicapai seseorang atau sekelompok orang dalam suatu organisasi/perusahaan sesuai dengan wewenang dan tanggung jawab masing-masing dalam melaksanakan tugas yang dibebankan kepadanya berdasarkan kecakapan, pengalaman, kesungguhan dan waktu (Nawawi, 2006:65). Seseorang yang memegang posisi manajerial diharapkan mampu menghasilkan suatu kinerja manajerial. Kinerja manajerial adalah kinerja para individu anggota organisasi dalam kegiatan-kegiatan manajerial, antara lain perencanaan, investigasi, pengkoordinasian, evaluasi, pengawasan, pengaturan staf (staffing), negosiasi dan perwakilan (Suprantiningrum et al., 2003)

\section{Total Quality Management (TQM)}

Total Quality Management (TQM) merupakan suatu pendekatan dalam menjalankan usaha yang mencoba untuk memaksimumkan daya saing organisasi melalui perbaikan terus-menerus atas produk, jasa, manusia, proses, dan lingkungannya. TQM merupakan suatu sistem yang dirancang sebagai kesatuan yang memfokuskan pada pendekatan pelanggan dengan meningkatkan kualitas produk dan pelayanan. TQM meningkatkan produktivitas dengan mengurangi perilaku yang tidak produktif (Tjiptono dan Diana, 2003:4).

\section{Sistem Penghargaan}

Sistem penghargaan adalah pemberian kompensasi kepada manajer yang terdiri atas pembayaran tetap saja dan pembayaran tetap ditambah variabel yang jumlahnya ditentukan berdasarkan kinerja manajer (Kurnianingsih et al., 2001). Sistem penghargaan adalah pemberian kompensasi baik financial maupun non financial kepada manajer atau karyawan untuk memotivasi agar kinerja menjadi lebih baik (Wijayanti, 2011).

\section{METODE PENELITIAN \\ Populasi dan Sampel}

Teknik penentuan sampel dalam penelitian ini adalah sampling jenuh. Sampling jenuh adalah teknik penentuan sampel apabila semua anggota populasi digunakan sebagai sampel (sensus) (Sugiyono, 2005:78). Jumlah populasi dalam penelitian ini sebesar 66 
responden yang terdiri dari manajer dan staf dengan level terendah supervisor. Data penelitian dikumpulkan dengan menyebarkan 66 kuesioner kepada manajer dan staf terendah adalah supervisor di masing-masing supermarket yang menjadi obyek penelitian. Kuesioner yang kembali adalah sebanyak 66 kuesioner. Dengan demikian jumlah kuesioner yang kembali itulah merupakan sampel dalam penelitian ini.

\section{Definisi Operasional Variabel Kinerja Manajerial}

Kinerja manajerial dalam penelitian ini adalah kinerja manajer dalam kegiatankegiatan manajerial. Kinerja manajerial diukur dengan delapan indikator yaitu perencanaan, investigasi, pengkoordinasian, evaluasi, pengawasan, pengaturan staf, negosiasi, dan perwakilan. Indikator kinerja manajerial diukur dengan menggunakan indicator self rating (Sumarno, 2005). Pengukuran indikator dilakukan dengan menggunakan skala interval dengan rentang 1 sampai 9, dimana rentang dari 1 sampai dengan 3 menunjukkan kinerja di bawah rata-rata, 4 sampai dengan 6 menunjukkan kinerja rata-rata, dan 7 sampai dengan 9 menunjukkan kinerja di atas rata-rata.

\section{Total Quality Management (TQM)}

TQM adalah pengelolaan suatu sistem organisasi dengan komitmen penuh terhadap peningkatan yang berkelanjutan serta berusaha secara total untuk memenuhi kebutuhan konsumen. TQM diukur dengan tujuh indikator yaitu fokus pada pelanggan, obsesi terhadap kualitas, komitmen manajemen puncak, kerjasama tim (teamwork), perbaikan berkesinambungan, pendidikan dan pelatihan, serta adanya keterlibatan dan pemberdayaan karyawan. Indikator diukur dengan menggunakan skala interval (nilai $1=$ sangat tidak setuju, nilai $2=$ tidak setuju, nilai $3=$ cukup setuju, nilai $4=$ setuju, nilai $5=$ sangat setuju) (Jogiyanto, 2007:67).

\section{Sistem Penghargaan}

Sistem penghargaan adalah suatu sistem atau program yang diberikan manajemen dengan memberikan tambahan penerimaan bagi karyawan atau manajer sebagai upaya untuk lebih meningkatkan kinerjanya. Sistem penghargaan diukur dengan indikator financial (berupa gaji, upah, tunjangan) dan non financial (berupa pengakuan, promosi, dukungan). Indikator diukur dengan menggunakan skala interval (nilai $1=$ sangat tidak setuju, nilai $2=$ tidak setuju, nilai $3=$ cukup setuju, nilai $4=$ setuju, nilai 5 = sangat setuju) (Jogiyanto, 2007:67).

\section{Uji Hipotesis}

Penelitian ini menggunakan analisis regresi sederhana untuk melihat pengaruh variabel independen terhadap variabel dependen yaitu pengaruh Total Quality Management (TQM) terhadap kinerja manajerial. Sementara itu, untuk menguji pengaruh variabel pemoderasian yaitu sistem penghargaan terhadap hubungan antara TQM terhadap kinerja manajerial digunakan uji interaksi/Moderated Regression Analysis (MRA).

Persamaan regresi sederhana yang digunakan untuk menentukan pengaruh variabel TQM terhadap kinerja manajerial adalah, sebagai berikut :

$\mathrm{Y}=\mathrm{a}+\mathrm{b}_{1} \mathrm{X}_{1}+\mathrm{e}$

(Wijaya, 2011:92)

Persamaan statistika dalam uji interaksi yang digunakan untuk menentukan variabel pemoderasian dalam hubungan TQM terhadap kinerja manajerial adalah, sebagai berikut :

$$
\mathrm{Y}=\mathrm{a}+\mathrm{b}_{1} \mathrm{X}_{1}+\mathrm{b}_{2} \mathrm{X}_{2}+\mathrm{b}_{3} \mathrm{X}_{1} \mathrm{X}_{2}+\mathrm{e}
$$$$
\text { (Ghozali, 2006:164) }
$$

Dimana :

$\mathrm{Y} \quad=$ Kinerja manajerial

$\mathrm{X}_{1} \quad=$ Total Quality Management (TQM)

$\mathrm{X}_{2} \quad=$ Sistem penghargaan sebagai variabel moderasi

$\mathrm{X}_{1} \mathrm{X}_{2}=$ Interaksi $\mathrm{TQM}$ dengan sistem penghargaan

$$
\begin{array}{ll}
\mathrm{a} & =\text { Konstanta } \\
\mathrm{e} & =\text { Error }
\end{array}
$$

\section{HASIL DAN PEMBAHASAN}

Pengujian Hipotesis Pertama (H1)

Penelitian ini menggunakan analisis regresi sederhana untuk menentukan pengaruh variabel TQM terhadap kinerja manajerial. 
Hasil analisis selengkapnya dapat dilihat pada Tabel 1 dan 2.

Tabel 1. Hasil Analisis Pengaruh TQM (X1) terhadap Kinerja Manajerial (Y)

Model Summary ${ }^{b}$

\begin{tabular}{|l|c|c|c|c|}
\hline Model & R & $\begin{array}{c}\text { R } \\
\text { Square }\end{array}$ & $\begin{array}{c}\text { Adjusted R } \\
\text { Square }\end{array}$ & $\begin{array}{c}\text { Std. Error } \\
\text { of the } \\
\text { estimate }\end{array}$ \\
\hline 1 & $.901^{\mathrm{a}}$ & .812 & .810 & .143033 \\
\hline
\end{tabular}

Sumber : Data Primer Diolah

Tabel 2. Coefficients ${ }^{a}$

\begin{tabular}{|cr|r|r|r|r|r|}
\hline Model & \multicolumn{2}{|c|}{$\begin{array}{c}\text { Unstandardi } \\
\text { zed } \\
\text { Coefficients }\end{array}$} & $\begin{array}{c}\text { Standardi } \\
\text { zed } \\
\text { Coefficien } \\
\text { ts }\end{array}$ & & \\
\hline & & B & $\begin{array}{c}\text { Std. } \\
\text { Error }\end{array}$ & Beta & t & Sig \\
\hline 8 & (Cons & .15 & .047 & & & \multicolumn{1}{|c|}{} \\
\hline & tant) & 8 & .020 & .901 & 5.37 & .00 \\
TQM & & .32 & & & 16.6 & .00 \\
& & 6 & & & 52 & 0 \\
\hline
\end{tabular}

Sumber : Data Primer Diolah

Hasil analisis regresi sederhana untuk menguji pengaruh TQM terhadap kinerja manajerial dalam Tabel 1. Menunjukkan bahwa nilai Adjusted $R$ Square $\left(\mathrm{R}^{2}\right)$ sebesar 0,810 yang berarti variabilitas/perubahan kinerja manajerial (Y) dapat dijelaskan oleh TQM $\left(\mathrm{X}_{1}\right)$ sebesar 81 persen dan sisanya 19 persen dijelaskan oleh variabel lain yang tidak dimasukkan dalam model penelitian.

Nilai thitung pada variabel TQM $\left(\mathrm{X}_{1}\right)$ sebesar 16,652 dengan tingkat signifikan sebesar 0,000 $(<0,05)$. Hal ini berarti TQM $\left(\mathrm{X}_{1}\right)$ secara parsial berpengaruh secara positif dan signifikan terhadap kinerja manajerial (Y). Artinya peningkatan penerapan TQM akan dapat meningkatkan kinerja manajerial.

Pengujian Hipotesis Kedua $\left(\mathrm{H}_{2}\right)$

Hasil analisis selengkapnya untuk menentukan pengaruh TQM terhadap kinerja manajerial dengan dimoderasi oleh sistem penghargaan dapat dilihat pada Tabel 3, 4 dan 5.

Tabel 3. Hasil Analisis Pengaruh TQM (X1) terhadap Kinerja Manajerial (Y) dengan Dimoderasi oleh Sistem Penghargaan $\left(\mathrm{X}_{2}\right)$ Model Summary ${ }^{b}$

\begin{tabular}{|l|c|r|r|c|}
\hline Model & $\mathbf{R}$ & $\begin{array}{c}\text { R } \\
\text { Square }\end{array}$ & $\begin{array}{c}\text { Adjusted R } \\
\text { Square }\end{array}$ & $\begin{array}{c}\text { Std. Error } \\
\text { of the } \\
\text { estimate }\end{array}$ \\
\hline 1 & $.917^{\mathrm{a}}$ & .842 & .834 & .133500 \\
\hline
\end{tabular}

Sumber : Data Primer Diolah
Tabel 4. ANOVA ${ }^{b}$

\begin{tabular}{|l|c|c|c|c|r|}
\hline Model & $\begin{array}{c}\text { Sum of } \\
\text { Square } \\
\text { s }\end{array}$ & $\begin{array}{c}\text { D } \\
\text { f }\end{array}$ & $\begin{array}{c}\text { Mean } \\
\text { Squar } \\
\text { e }\end{array}$ & F & Sig. \\
\hline $8 \quad$ Regressi & 5.877 & 3 & 1.959 & 109.92 & .000 \\
on & 1.105 & 6 & .018 & 4 & \\
Residual & 6.982 & 2 & & & \\
Total & & 6 & & & \\
\hline
\end{tabular}

Sumber : Data Primer Diolah

Tabel 5. Coefficients ${ }^{a}$

\begin{tabular}{|c|r|r|r|r|r|}
\hline Model & \multicolumn{2}{|c|}{$\begin{array}{c}\text { Unstandardized } \\
\text { Coefficients }\end{array}$} & $\begin{array}{c}\text { Standardized } \\
\text { Coefficients }\end{array}$ & & \\
\hline & B & $\begin{array}{c}\text { Std. } \\
\text { Error }\end{array}$ & Beta & \multicolumn{1}{|c|}{ t } & Sig. \\
\hline $8 \quad$ (Constant) & .222 & .112 & & & \\
TQM & .069 & .086 & .191 & .986 & .051 \\
SP & 1.044 & .358 & .593 & .425 \\
Moderat 1 & .036 & .053 & .143 & .681 & .005 \\
\hline
\end{tabular}

Sumber : Data Primer Diolah

Tabel 3. Menunjukkan nilai adjusted $R$ Square $\left(\mathrm{R}^{2}\right)$ sebesar 0,834 , hal ini berarti 83,4 persen variasi/perubahan kinerja manajerial dapat dijelaskan oleh variabel TQM, sistem penghargaan, interaksi TQM dan sistem penghargaan, sedangkan sisanya 16,4 persen dijelaskan variabel lain yang tidak dimasukkan dalam model penelitian.

Uji Anova atau $F$ test pada tabel 4. Menghasilkan nilai $F_{\text {hitung }}>F_{\text {tabel }}(109,924>$ 2,76) dengan tingkat signifikansi 0,000. Karena $F_{\text {hitung }}>F_{\text {tabel }}$ dan probabilitas signifikansi jauh lebih kecil dari 0,05, maka model regresi dapat digunakan untuk memprediksi kinerja manajerial atau dapat dikatakan bahwa TQM, sistem penghargaan, interaksi TQM dengan sistem penghargaan secara bersama-sama berpengaruh terhadap kinerja manajerial.

Dari Tabel 5. Dapat dijelaskan bahwa hanya variabel sistem penghargaan yang berpengaruh secara signifikan terhadap kinerja manajerial. Variabel TQM memberikan nilai koefisien parameter 0,069 dengan tingkat signifikansi 0,425 dan variabel sistem penghargaan memberikan nilai koefisien parameter 1,044 dengan tingkat signifikansi 0,05 . Variabel moderat1 memberikan nilai koefisien parameter sebesar 0,036 dengan tingkat signifikansi sebesar 0,498 (> 0,05). Variabel moderat1 yang merupakan interaksi TQM dan sistem penghargaan ternyata tidak 
signifikan, sehingga dapat disimpulkan bahwa variabel sistem penghargaan tidak mempengaruhi hubungan (tidak memoderasi) TQM terhadap kinerja manajerial.

\section{PENUTUP}

\section{Kesimpulan}

Berdasarkan masalah, pembahasan, dan hasil analisis data mengenai pengaruh Total Quality Management (TQM) terhadap kinerja manajerial dengan pemoderasi variabel sistem penghargaan pada supermarket di Mataram, maka dapat diambil kesimpulan sebagai berikut:

1. TQM berpengaruh signifikan terhadap kinerja manajerial. Artinya TQM yang diterapkan dalam supermarket mempunyai peran penting dalam meningkatkan kinerja manajerial untuk mewujudkan tujuan yang telah ditetapkan. Produk berkualitas yang dapat memenuhi kebutuhan dan kepuasan konsumen akan menimbulkan pembelian yang berkelanjutan, sehingga dapat meningkatkan produktivitas perusahaan. Dengan demikian penerapan TQM akan berdampak pada peningkatan kinerja manajerial, sehingga meningkatkan penghasilan dan tujuan akhirnya adalah untuk meningkatkan laba agar dapat terus berjalan dalam persaingan perdagangan yang semakin ketat.

2. Sistem penghargaan tidak mempengaruhi hubungan TQM terhadap kinerja manajerial. Artinya dengan diterapkannya sistem penghargaan maka tidak akan berpengaruh pada TQM terhadap kinerja manajerial, sehingga dapat dijelaskan bahwa ternyata tidak cukup dengan sistem penghargaan tinggi dan dibarengi dengan TQM tinggi akan dapat mempengaruhi kinerja manajerial. Dengan demikian penerapan TQM dalam supermarket telah mampu meningkatkan kinerja manajerial walaupun tidak disertai dengan pemberian sistem penghargaan yang tinggi.
DAFTAR PUSTAKA

[1] Malik, Shahab Alam, Muhammad Zahid Iqbal, Razia Shaukat,\&Jia Yong, TQM Practices and Organizational Performance: Evidence From Pakistani SMEs, International Journal of Engineering and Technology, 2010, Vol. 10 No. 04: 26-31.

[2] Karahan, Mehmet\&Nevzat Tetik, The Determination of The Effect Level on Employee Performance of TQM Practices with Artificial Neural Networks: A Case Study on Manufacturing Industry Enterprises in Turkey, International Journal of Business and Social Science, 2010, Vol. 3 No. 7: 133-142.

[3] Nurfitriana, Ina, Grahita Chandrarin\&Hanif Ismail, Teknologi Informasi, Sistem Pengukuran Kinerja dan Penghargaan Sebagai Pemoderasi Hubungan antara TQM dengan Kinerja Manajerial, Akuntabilitas , 2005, Vol. 5 No. 1:17-34.

[4] Nawawi, Hadari, Evaluasi dan Manajemen Kinerja di Lingkungan Perusahaan dan Industri, Gadjah Mada University Press, Yogyakarta, 2006.

[5] Suprantiningrum, Pengaruh Total Quality Management Terhadap Kinerja Manajerial dengan Sistem Pengukuran Kinerja dan Sistem Penghargaan (Reward) Sebagai Variabel Moderating (Studi Empiris pada Hotel di Indonesia) (Tesis), Program Pascasarjana Universitas Diponegoro. Semarang, 2003.

[6] Tjiptono, Fandy\&Anastasia Diana, Total Quality Management, Penerbit Andi, Yogyakarta, 2003, Edisi Kelima.

[7] Kurnianingsih, Retno\&Nur Indriantoro, Pengaruh Sistem Pengukuran Kinerja dan Sistem Penghargaan Terhadap Keefektifan Penerapan Teknik Total Quality Management Studi Empiris pada Perusahaan Manufaktur di Indonesia, Sosiohumanika, 2001, Vol. 14 No. 2.

[8]

[9] Wijayanti, Elly, Pengaruh Sistem Pengukuran Kinerja dan Sistem Penghargaan Terhadap Keefektifan Penerapan Teknik Total Quality 
Management (TQM) (Skripsi), Fakultas

Ekonomi Universitas Pembangunan

Nasional "Veteran", Jakarta, 2011.

[10] Sugiyono, Metode Penelitian Bisnis. CV. Alfabeta, Bandung, 2005.

[11]Sumarno, J., Pengaruh Komitmen Organisasi dan Gaya Kepemimpinan Terhadap Hubungan antara Partisipasi Anggaran dan Kinerja Manajerial (Studi Empiris Pada Kantor Cabang Perbankan Indonesia di Jakarta), Simposium Nasional Akuntansi VIII, 2005.

[12] Jogiyanto, Metodologi Penelitian Bisnis, BPFE, Yogyakarta, 2007.

[13]Wijaya, Tony, Cepat Menguasai SPSS 19 untuk Olah dan Interpretasi, Cahaya Atma, Yogyakarta, 2011.

[14] Ghozali, Imam, Aplikasi Analisis Multivariate dengan Program SPSS, Badan Penerbit Universitas Diponegoro, Semarang, 2006. 